DOI: https://doi.org/10.47264/idea.lassij/4.1.12

Vol. 4, No. 1, (January-June 2020): 130-139

Research Article

URL: https://www.ideapublishers.org/index.php/lassij

\title{
Does the Factor of Religion Affect Women Leadership? A Case Study of Dir Lower, Pakistan
}

\author{
Ahmad Hassan Khattak ${ }^{1}$, Azizullah Jan*2, H. Mohsin Zia Qazi ${ }^{3}$ \& Ihsan Ullah Khan ${ }^{4}$ \\ 1. Department of Islamic Studies, Hitec University, Taxila Cantonment, Pakistan. \\ 2. Department of Sociology, University of Peshawar, Peshawar, Pakistan. \\ 3. Department of Islamic Studies, Aabroo-e-Millat School System, Rawalpindi, Pakistan. \\ 4. Department of Sociology, FATA University, Dara Adam Khel, Kohat, Pakistan.
}

Published Online: October 28, 2020

\begin{abstract}
Political support is one of the significant factors of strengthening and makes mindfulness among females about their privileges in the general public. The current investigation was conducted on the religious factor, affecting the women leadership and active participation in politics in district Dir Lower, Khyber Pakhtunkhwa, Pakistan. The sample size for the information assortment was 130 respondents through used the standard contrived by Sakaran. After assortment, the information was prepared through SPSS and organized just as introduced in rates and frequencies for better understanding. A Chi-square test was utilized for estimating the relationship between autonomous variables and ward factors. The investigation recommended that adjustment in female proper education can move about better mindfulness and fearlessness. The examination additionally suggests the noteworthy contribution of government and non-government organizations for initiating women bunches, just as expanding women mindfulness level, political cooperation mindfulness, and learning abilities. The examination recommended that a women head can all the more likely engage women later on, just as a female competitor, can more readily tackle their issues when contrasted with a male.
\end{abstract}

Keywords: Women in Politics, Women Empowerment, Women Leadership, Religion \& Politics, Gender Role in Religion.

\section{Introduction}

Equivalent access to political interest is viewed as fundamental to the majority rules system and by expansion to political and social strength and monetary turn of events. As a general rule, political support and access to dynamic are unequivocally affected by the nearby impression of sexual orientation, race, and religion. In malice of the detail that these disputes, separately and all things considered, are vital to understanding governmental issues in the Pacific district, they are frequently dismissed in strategy and help banter as 'social' factors that are, best case scenario minor to legislative issues (Thomas, 2002). As indicated by the examination directed by Dijkstra and Hanmer (1997), for the most part, women' investment in legislative issues when contrasted with men is a lot of confined. Women in government in the forefront time frame are all things considered underrepresented in abundant republics all over the world. In countless of these countries, females have had missing exposed entrances in the communal venture, particularly in annoying administrative privileges and force in the governing body and different 
establishments. Furthermore, faith expects a noteworthy activity in the possession of females in the household. The religious activities in Islam are masculine-driven and are clear concerning the division of labour and responsibility based on gender, efficiently decontaminating man of his word quality (Mukhopadhyay, 2016).

Nonetheless, a false notion over females' position and low performance is still common. The governing body has been showing different approaches to orientation through sanctioning for bringing the women to standard region. What's more, females are as yet dropping overdue concerning their degree of investment. Women in the political field at the early stage have demonstrated some achievement. The ongoing decentralization worldview likewise centres the women' interest in the neighbourhood physiques for the reason for conventional the communal textures at the fundamental level to pledge females to entirely yield a notice. Furthermore, it would also endeavour to examine the candid accidental that whether females could be a suitable supernumerary to men in administrative concerns while machinating certain approach application. Women are encouraged to utilize "purdah" when all set outside from houses, with the target that they can cover themselves from others (Shamim and Nasreen, 2002; Shehabuddin, 1999).

In the $21^{\text {st }}$ century, females are face hurdles in their regulatory involvement everywhere throughout the world. The money-related components ascend as a deterrent to the progress of women. As demonstrated by the report of the Inter-Parliamentary Union, 2017 (The IPU is the all-inclusive relationship of Parliaments which was set up in 1889), by and large, the female depiction rate is 23.6 percent. This base depiction shows that Women need noteworthy separation to achieve correspondence in authoritative issues. For the equal collaboration of women in technique advancing to progress sexual direction sensible government endeavours are being made to fabricate backing of women, for instance, regulatory measures and so on (Jan \& Khan, 2020).

According to Aristotle, "In the contrasts between genders, men are viewed as better and more in nature, while women are thought little of". The sexual orientation share is being executed at an astounding rate all through the world. It is viewed as a significant approach measure to expand the compass of women in dynamic bodies. The essential motivation behind the quantity framework is to advance cooperation in women' legislature. To include women in legislative issues, in a political circumstance, the share is applied briefly until the hindrances to women' political cooperation are expelled. Many creating nations on the planet have guaranteed amount at the national or sub-national level with the goal that sex can be guaranteed. In many created nations, ideological groups have deliberately received standards, women can be useful in political strengthening. Women will get reinforcement in the administrative issues just if the women get a reservation in legislative issues. Social impediments can in like manner be crushed when the establishment of women participation are brought forward and started up in administrative issues (Kumar, 2017). Besley and Case (2000) showed that "the portions of women in the upper and lower statehouses are profoundly huge indicators of an express specialists' remuneration strategy". In many social orders, the activities of genders are separated in an outside and within the home.

Subsequently, the social flexibility of women is bound and controlled. It is seen that men are given better preparation to fight. Women have gotten subject to men because of nonattendance of benefits outside the house, and from this time forward, in the social, money-related, and political regions, men become the reason of force. The activity of women in the course of action 
of budgetary and social methodologies is insignificant. Due to being unendingly from women's dynamic bodies, they don't get any chance to raise their inclinations or advance their help in administrative issues. Men rule the plan of organization in India. It is required for women to ensure a ton of women's fortifying (Kumar, 2017).

A review of history shows that "God" has been a prevalent factor in whether women check out legislative issues. Division of house of prayer and state is a legend in various countries on the planet, and, in the minds and hearts of many, a disastrous target. In specific spots, duty and certainty catalyse women to take up an explanation, political or something different. In various spots, the "individuals calling the shots" bring understandings of magnificent books to deny women's political intrigue - and dispatch women to their homes and nuclear family commitments. With everything taken into account, does religion, in the long run, actuate or hinder women's political speculation? This conjuring of religion, be that as it may, has wind up being a twofold edged cutting edge for women. While various systems have fought long and hard for the blend of the exacting statute into legitimate codes, women at present bear the heaviness of overturning logically prescriptive and restrictive sexual direction guidelines that have been organized as law. This consolidates some sort of the Family Code, which is accessible all through the Arab world. Bring of religion has in like manner carried along with solutions for women concerning dress, adaptability, and sexuality. For example, all through the Muslim diaspora, the spread is making a bounce back, and religion is politicizing women who were not previously publicly secured. Analysts, activists, and experts continue pondering the conversation, quality, and question of this material (Djupe \& Grant, 2001). Finally, a some of the women are constrained from an urban, social and political interest in settings where severe fundamentalisms are on the climb.

Characteristically there is no complexity among the man and women and both are getting a charge out of political rights as pictured in Act 34 of Pakistan's 1973 Constitution which communicates that all of those methods should be in every practical sense completed for which women fortifying to be ensured for that all methods should get took a gander at. Hence, article twenty-five of the constitution of Pakistan also kept an eye on that every occupant of this country must profit every opportunity paying little heed to cost and tenet, sex, religion, etc. similarly as proportional under the watchful eye of the law with no such of sort of isolation (Rehman, 1973). As the father of the nation for instance Quaid-e-Azam was stressing the hugeness of women support being created of a nation. The property the view that country can't be created until the women are not taken part in different social statuses as like men (World Times, 2014; Sheikh, 2016). Besides, Mahmood (2004) stated that the Nations cannot develop until women are not in politics and fully empowered. Equally, Saleem (2010) articulated that, when women are neglected from politics it will be negative consequences on national, provincial, and local development. Furthermore, misinterpretation of religious beliefs, rigid customs, women immobility, and patriarchy is a basic source of female disparity in various aspects of life especially in education (Jejeebhoy \& Sathar, 2001). The cultural norms consistently facilitate such a smooth environment from stratification and privateness of women, which are embedded in religion. The clergies take support of religion to oppose and oppress the women's voice (Naz et al, 2012).

Paxton and Hughes (2007) featured that; religion kills women to take an interest in numerous parts of social, political, financial strengthening in life all through the world. As indicated by Farzana (2005) and Islam (2010) was of the sentiment that strict and social imperatives keep women out of legislative issues. What's more, Paterson (2008) was expressed that, the 
philosophical and customary methodology of faith making obstructions to women introduction in an administrative setting. Besides, Naz et al. (2012) enunciated that the Pakhtun set of accepted rules and Islamic worth are in combination don't allow women political mainstreaming. Although, from morning to night, they are occupied in residential errands and child cares. With regards to political worldview, women' portrayal has come about inconsistent in contrast with men. Women have political graveness concerning surveying of vote, challenge political race openly, and battle for governmental exercises. Thus, Kalam (2014) uncovered that Islamic radicalism is a simple impediment in the method of women getting strengthening. In logical inconsistency, Islam offers total correspondence to both (male and female) yet incidentally, a portion of the strict gatherings and pseudo-strict people groups forced limitations on women from support in governmental issues. So, Khan (2014) also featured that the speech of mullahs is a holy speech in larger part in rural zones of Khyber Pakhtunkhwa. What is more, fear-based is that the oppressors and extremists and their standard perspectives don't permit women to a political circle of life individually. Besides, strict follower misleads people in general by utilizing the name of religion Islam to persevere their grace. Implies that, in Pakistani society, religion and legislative issues go hand in hand and demolition of women is one of the outcomes.

The government officials explicitly the Islamic gatherings utilized twofold gauges which deceive women for their political achievement. In standard conversation and media meets, the pioneers of these strict gatherings were guarantee cap Islam ensures exceptional rights and common allotment to women. Amusingly, these gatherings first imprint the privileges of women with regards to the parliament. For instance; in 2002, the Khyber Pakhtunkhwa gettogether, where strict gatherings were administering passed a bill in which, women were not to be permitted to visit male specialists only for respect. Pakistani culture has confidence in a division of both sexual orientations under the pretence of religion. It is a far model, strictly instructed that females ought to watch Purdah and requesting their confinements as far as access to assets even might be their failures to choose their own fairly looking for transcription from men (Shaheed et al., 2009). Youngsters in respect of females are related to being mothers, mates, and workers under others' ability. Their home nuclear family tasks are boundless; regardless, when energetic, they routinely help in the home and care for more young kinfolk, and average people using housekeeper employees track down that the woman for the most part brings her daughter along to help. In any case, paying little heed to this fundamental and continuing with work, women are, continually showed up as more helpless than men, which consequently, legitimize "safeguard" and hesitance to deliver women out of the house. In by far most of the countries, the detachment among individuals is separate by socially supported limit contrasts in dress and individual lead norms. Customs of "purdah" exist among Muslims, yet likewise among Hindus in provincial India, where women in logically "fair position" out of date families are conceivable to cover their faces before men, and Sari closes are worn ludicrous, at times covering the face (Frank, 2009). Women maintain a strategic distance from the investment of non-family folks. Severe fundamentalism raises this purdah direct and tries to hold women out of the open and public movement. Women following new, "revealing" styles have been attacked by fundamentalists taking everything into account (Dijkstra \& Hanmer 1997). All in all, severe fundamentalism is foreboding to women taking an interest in legislative issues (Hardgrave, 1993).

\section{Theoretical Framework (Liberal Feminist Theory)}

The liberal women's activist hypothesis is imperative to this examination because in the liberal 
women's activist hypothesis they centre on the rights and qualities of the female when contrasted with distinction amongst the two genders (female and male). In the abundant woman's rights hypothesis, they referenced that in male-centric social orders they have authority upon their female individuals yet all over again the male individuals imagine that correspondence of both the genders is the contest for man-controlled society (Kivoi, 2014). Liberal women's liberation hypothesis centres on the squeezing sexual orientation profession their adjustment that confined male prevailing society for females. Liberal women's activists need to be mindful of the severe women about their low confidence, uneasiness, dread of accomplishment, and low certainty of taking interest in the legislative issues of the society. As in Pakhtun society, the socialization design bolsters the male individuals and considers them with a statement as "child as a firearm" through this statement and the limited culture it is exceptionally hard for females to take an interest in the legislative issues of society like the men do (Kivoi, 2014).

\section{Material and Methods}

The study was delimited to the 37 union councils of all the seven tehsils of District Lower Dir. The defendants involved those females who had confronted in close government judgments in the engrossed on locale. The facts were gathered through a basic irregular examining procedure where the absolute populace, was 196 in the unbiased ground of the study. The all-out populace sample size of 130 councillors was taken through criteria designed by Sekaran and Bougie (2016). The optional information showed that 196 females had defied in the nearby body races in the investigation territory. The complete sample size was disseminated to different Union Councils on the proportionate premise. To get the prime information talk with a plan was created considering the targets and various factors examined in the writing survey. The validity and reliability of the data collection tools were pretested and reviewed by several experts for the sack to collect relevant and targeted information. The tool for data collection was the interview schedule due to some respondents were not educated well and the empirical data was analyzed through SPSS. In descriptive statistics, the percentage and frequency of collected data were examined and inferential statistics the Bi-variate analyses were made. In bivariate analyses, the Chi-square $\chi 2$ test by McCall and Kagan (1975), was used to determine the association between the dependent variable (females' contributions in active politics) and independent variables (religious constraint).

\section{Analysis and Discussion}

This section of the article gives a detailed discussion about the univariate and bivariate analysis of the field data for this study.

\subsection{Uni-Variate Analyses}

The empirical data of the above table is related to female participation in political activities in the light of strong believers of the religion. In the first response of the above table most of the respondents i.e., 76.9 percent agreed with the statement that their decision and participation in different outdoor activities were restricted due to local perceptions of the masses. Similarly, some of the participants i.e., 17.7 percent did not agree and the remaining 5.4 percent were neutral regarding the statement. In the next question of the table majority of the interviewees i.e., 79.2 percent agreed with the statement that religion restricted females from political activities. Furthermore, 12.3 percent did not agree while the rest of the participants i.e., 08.5 
percent did not disclose their opinion regarding the question. In the third question of the above table most of the interviewees i.e., 56.2 percent agreed with the question, while 33.8 percent did not agree and the remaining 10.0 percent did not participate to give any opinion regarding the question. In the fourth statement, the majority of the respondents i.e., 65.8 percent of the respondents agreed with the question that the public who have strong faith in religion did not support any kind of involvement in politics. Also, 28.5 percent of respondents did not agree while 06.2 percent were neutral regarding the question asked from them. In the sixth statement of the above table most of the respondents i.e., 46.9 percent agreed that religious extremism creates hurdles in the involvement of females in political activities. Similarly, the secondhighest figure i.e., 40.0 percent did not agree and the remaining 13.1 percent did not share their views regarding the question. In the last statement of the above table majority of the respondents i.e., 53.8 percent agreed that most of the parties use the public for their benefit. Additionally, 33.1 percent of the respondents did not agree while few of the respondents i.e., 13.1 percent were neutral regarding the statement.

Table-1: Women Participation in Politics in the light of Religion

\begin{tabular}{|l|l|l|l|l|l|l|l|}
\hline Statements & \multicolumn{2}{|c|}{ Agree (\%) } & \multicolumn{2}{|c|}{$\begin{array}{c}\text { Disagree } \\
(\%)\end{array}$} & $\begin{array}{c}\text { Neutral } \\
(\%)\end{array}$ & Total \\
\hline $\begin{array}{l}\text { Political interest and access to dynamic are } \\
\text { unequivocally impacted by nearby discernments } \\
\text { sex, race and religion. }\end{array}$ & 100 & 76.9 & 23 & 17.7 & 07 & 5.4 & 130 \\
\hline Religion restricted women participation in politics & 103 & 79.2 & 16 & 12.3 & 11 & 08.5 & 130 \\
\hline $\begin{array}{l}\text { Religion consider men as superior and fit for politics } \\
\text { as compared to women. }\end{array}$ & 73 & 56.2 & 44 & 33.8 & 13 & 10.0 & 130 \\
\hline $\begin{array}{l}\text { Devotion and strong faith on religion put women } \\
\text { apart from politics }\end{array}$ & 85 & 65.8 & 37 & 28.5 & 08 & 06.2 & 130 \\
\hline $\begin{array}{l}\text { Islamic extremism is the basic impediment to female } \\
\text { getting empowerment in politics }\end{array}$ & 61 & 46.9 & 52 & 40.0 & 17 & 13.1 & 130 \\
\hline $\begin{array}{l}\text { The Islamic parties' leaders misguide females for } \\
\text { their success }\end{array}$ & 70 & 53.8 & 43 & 33.1 & 17 & 13.1 & 130 \\
\hline
\end{tabular}

\subsection{Bi Variate Analysis}

The empirical data of the above table is about the religious followers and the participation of the female in politics. In the first statement of the table, there was a significant association $(\mathrm{p}=0.029)$ found between the access to decision making (politics) of the female strongly influenced by the local masses with the participation of the female in politics. The finding of the above statement is supported by the research of Thomas (2002). According to his findings, for the development of any society both the gender have to participate equally in every walk of life. When there is equality between the genders then they will play their role positively and the result will be the happiness of the entire public. Furthermore, he was of the view that in most societies there is just a concept of equality but in reality, there is a patriarchal system. Mostly the dominancy of the males suppressed the views and decisions of the female in rural areas especially, where there are strict rules and codes. In this study, the results are in the same line with the findings of Thomas (2002) where there is male dominancy in the Pashtun belt specifically, in Khyber Pakhtunkhwa, Pakistan where they neglected the females from decision making and outdoor participation in different activities.

Furthermore, there was a highly significant association $(\mathrm{p}=0.000)$ found between the religion 
restricted females from the participation outdoor activities with females participation in political activities. The result of the statement was supported by the findings of Dijkstra and Hanmer (1997). According to their results, male-dominant societies are always ignoring the females in different daily routine activities. Moreover, the misuse and misinterpretation of the religion by different religious scholars and political leaders also play an important role in edging the females from the core of political activities. They mentioned the example of Bangladesh that which is an Islamic country and about 89 percent of the population is comprised of Muslims, where their leaders did not give more importance to females to participate in political activities.

Additionally, a significant association $(\mathrm{p}=0.028)$ found between the misinterpretation of the religion plays an important role to suppress the female and the indulgence of females in politics. The result of the above statement is supported by the findings of Kumar (2017). According to him, the great philosopher Aristotle quoted that "In the differences between sexes, men are considered better and more in nature, while women are underestimated". Kumar found in his research that most countries ensured quota for females to participate in every activity with men, but in developing countries, this quota system is still not applied practically. Most of the time the narrow mind individuals and the misinterpretation of the religion, the males community sidelined the females from participation in politics. The most important thing is to create a quota for females in politics, somehow changes occurred there in the political system of Pakistan. Now, there are reserved seats for the females but again the male dominancy and the unawareness of the public creates hurdles in the way of females to actively participate in any political activity along with males.

Furthermore, in the fourth statement of the table- 2 , a significant association $(\mathrm{p}=0.006)$ was observed between the individuals who have strong faith in the religion which put females apart from political activities with the participation of women in politics. The study finding is supported by the empirical research of Djupe and Grant (2001). Their study also shows that the misinterpretation of the holy books of the different religion by their religious scholars to prohibit females from participation in political activities. Furthermore, all the members then blindly believe in their religious leaders and their elders. Due to their strong belief in their respective religion then the females consign to household activities. Now, the result of this study is in the same line with the findings of Djupe and Grant because in Pakhtun society the strict culture and the misinterpretation of the religion create hurdles for females to indulge in outdoor activities.

In the fifth statement of the table, a significant association $(\mathrm{p}=0.030)$ found between religious (Islamic) extremism creates hurdles in front of women to not participate in politics and female participation in political activities. The significant result is in the same line with the findings of Kalam (2014). According to him, religion creates hindrances to female participation in outdoor activities. But it is clear from the Islamic religion that both males and females are equal but some of the religious leaders prohibited females to be live there in the four walls of the home. Moreover, according to Khan (2014), in some regions of the Khyber Pakhtunkhwa Mullas (religious leaders) are considered sacred and all the members of the society then hear the voice and every act of the Mullas properly. The current study and the previous literature show that the unawareness and the strong belief of the females in their religious leaders put them away from political activities.

Additionally, different political parties' leaders often misguide and misuse the issue of women 
role in politics for their interest and success, there was a significant association $(\mathrm{p}=0.009)$ revealed with females participation in political activities. The study finding supported by Shaheed et al. (2009), their results shows that before the election of 2002 in Pakistan the religious leaders tried to convey a message regarding the rights of women. When they won the election then they pass a bill regarding the Purdah/veil of females. These religious leaders were of the view that female patients will not be able to go for a check-up with any male doctor. This shows double standards and the misinterpretations of the religion by these Mullahs and other religious leaders.

Table-2: Association Results of Women in Politics with Religious Point of View

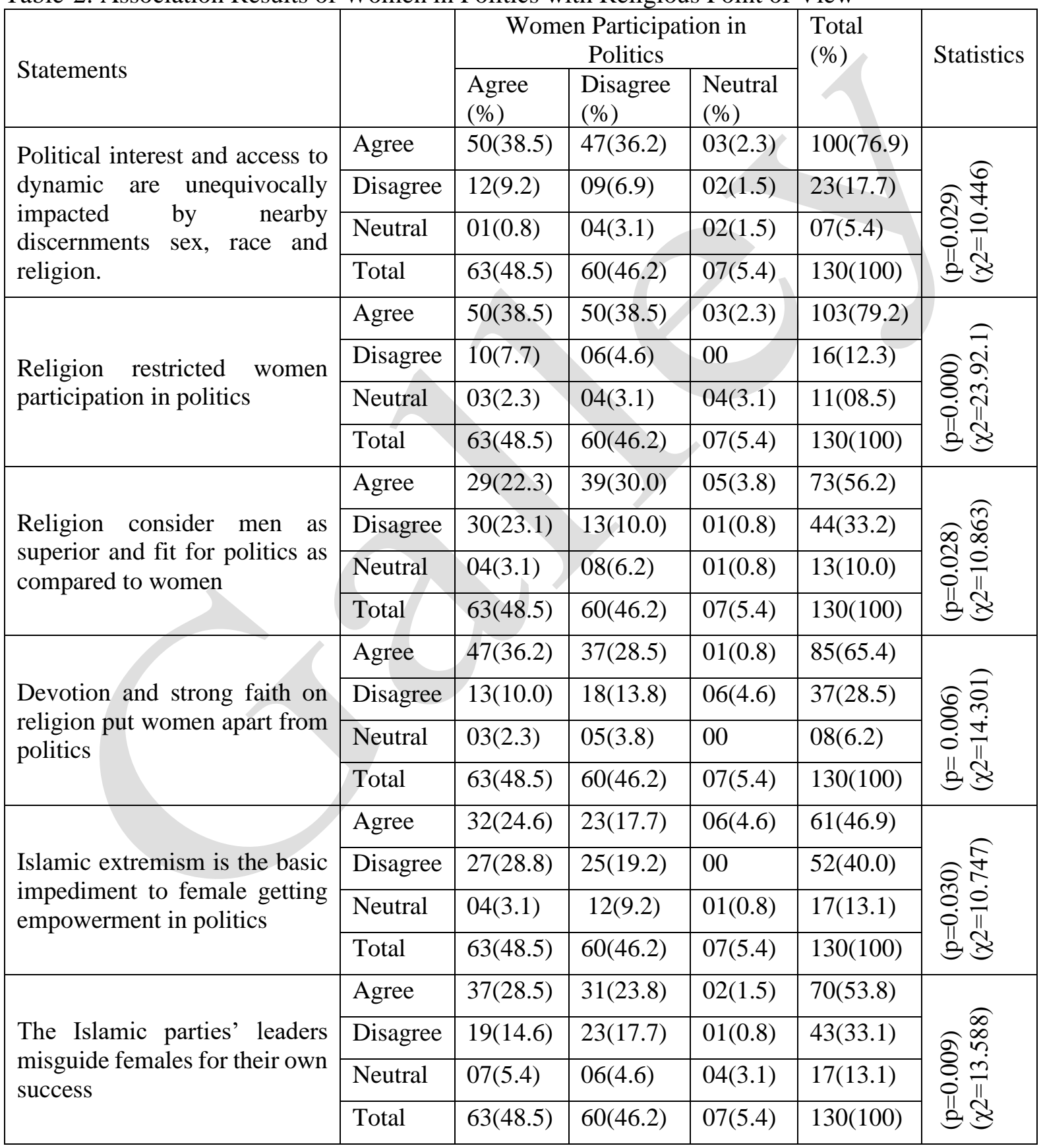

The figures in the table signify recurrence while figures in bracket indicate rate. The image $(\mathrm{P})$ speaks to the centrality level and $\left(\chi^{2}\right)$ speaks to the estimation of chi square. 


\section{Conclusion}

The study found that the women requisite role in governmental affairs is fortifying the society so that they can display their abilities external the household itself and should be given comparable positions by clearing out sexual direction division with them. Underneath the structure of various countries, women save the benefit to political, budgetary correspondence. This benefit should be executed by giving them the certified structure and those countries where there are no proportional rights, such laws should be made and gain from made countries that women are no shy of what others. Furthermore, checking out open-air like watching out for a gathering on some segment of women is at this point being treated as a no-no. It was further getting that religion enunciation of restricting women's occupation to nuclear family practices was in inescapability. These feelings were, "Purdah" for women and despicableness for the household and women to partake in governmental problems with dense assign correlation to severe distortion. We have found that nonappearance of training has furthermore become an obstacle to women's way. Women can't use their benefits properly on account of the nonappearance of guidance. The organization should coordinate to teach womenfolk. In reality, freedom of women in respect of active politics is necessary for the sack to search for remedies to confronted problems. Even though women had freedom, anyway strict misinterpretations were in common. All the organizations must bring the severe school for attention into a consensus. This attempt should expand in deciding the women' status with a unique job in all circles of life.

\section{References}

Besley, T., \& Case, A. (2000). Unnatural experiments? Estimating the incidence of endogenous policies. The Economic Journal, 110(467), 672-694.

Dijkstra, G., \& Hanmer, L. (1997). Measuring socio-economic gender inequality: towards an alternative to the UNDP gender-related development index. ISS Working Paper Series/General Series, 251, 1-30.

Djupe, P. A., \& Grant, J. T. (2001). Religious institutions and political participation in America. Journal for the Scientific Study of Religion, 40(2), 303-314.

Farzana, B. (2005). Women's political participation: Issues and Challenges. United Nations: DAWN, Expert meeting group, Bangkok, Thailand, 8-11 Nov. P 1

Frank, L. (2009). Sister Namibia magazine: a platform for the voices of women. Sister Namibia, 21(3), 6-10.

Hardgrave Jr, R. L. (1993). The Challenge of Ethnic Conflict: India-The Dilemmas of Diversity. Journal of Democracy, 4(4), 54-68.

Islam, F. (2010). Women empowerment revisited: A case study of Bangladesh. Development in practice, 20 (7), pp. 840-854

Jan, A., \& Khan, I. U. (2020). The Participation of Women in Politics in Respect of Religion;

A Case Study of Charsadda District of Khyber Pakhtunkhwa, Pakistan. Bannu University Research Journal in Islamic Studies, 7(1), 19-26.

Jejeebhoy, S. J., \& Sathar, Z. A. (2001). Women's autonomy in India and Pakistan: the influence of religion and region. Population and development review, 27(4), 687-712.

Kalam, A. (2014). Social norms and impediments of women development in Bangladesh. Int'l J. Soc. Sci. Stud., 2, 100

Khan, T. (2010). Socio-cultural determinants of women's empowerment in Punjab, Pakistan (Doctoral dissertation, University of Agriculture Faisalabad Pakistan). 
Kivoi, D. L. (2014). Factors impeding political participation and representation of women in Kenya. Humanities and Social Sciences, 2(6), 173-181.

Kumar, D. (2017). Participation of women in politics: Worldwide experience. IOSR Journal of Humanities and Social Science (IOSR-JHSS), 22(12), 77-88.

Mahmood, A. (2004). Political empowerment of women: A comparative study of south Asian countries. Pakistan Vision, 10(1), 151-152.

McCall, R. B., \& Kagan, J. (1975). Fundamental statistics for psychology (No. BF39. M3 1970). Harcourt Brace Jovanovich.

Mukhopadhyay, M. (2016). Mainstreaming gender or "streaming" gender away: feminists marooned in the development business. In The Palgrave Handbook of Gender and Development (pp. 77-91). Palgrave Macmillan, London.

Naz, A., Rehman, H. \& Alam, A., (2012). Gender and Development: Socio-Cultural, Economic, Religious and Political Impediments in Women's Empowerment and Gender Development: Journal (PUTAJ), 18. p.45.

Naz, I., Bano, A., Rehman, B., Pervaiz, S., Iqbal, M., Sarwar, A., \& Yasmin, F. (2012). Potential of Azotobacter vinelandii Khsr1 as bio-inoculant. African Journal of Biotechnology, 11(45), 10368-10372.

Paterson, R. (2008). Women's empowerment in challenging environments: A case study from Balochistan. Development in Practice, 18 (3), 333-344.

Paxton, P., \& Hughes, M. M. (2007). Women, Politics, and Power: A Global Perspective. Thousand Oaks, CA: Pine Forge

Rahman, F. (1973). Islam and the new constitution of Pakistan. Journal of Asian and African Studies, 8(3-4), 190-204.

Saleem, I. (2010). Women political participation. Daily times. Tuesday, August 27, 2013

Sekaran, U., \& Bougie, R. (2016). Research methods for business: A skill building approach. John Wiley \& Sons.

Shaheed et al. (2009). Women in Politics: Participation and Representation in Pakistan, An overview. Lahore: ShirkatGah-Women's Resource Centre.

Shamim, I., \& Nasreen, M. (2002). Gender and local governance: A new discourse in development. Journal of Social Studies-Dhaka, 50-87.

Shehabuddin, E. (1999). Contesting the illicit: Gender and the politics of fatwas in Bangladesh. Signs: Journal of Women in Culture and Society, 24(4), 1011-1044.

Sheikh, S. R. (2016). Pashtun Nationalism: Politics and Talibanization. Pakistan Horizon, 69(1).

Thomas, P. (2002). Introduction: Gender, Civil Society and Political Participation. Development Studies Network.

Wood, E., Tisdale, R., \& Jones, T. (Eds.). (2017). Active collections. Routledge.

World Times. (2014). http://jworldtimes.com/jwt2015/magazine-archives/jwt2014/july2014/women-in-pakistan-aspiring-to-a-better-tomorrow/ Research Journal Social Sciences Volume 7, No. (02) 101. 